\title{
Doppler echocardiographic measurement of flow velocity in the ascending aorta during supine and upright exercise
}

\author{
PATRICK J DALEY, KIRAN B SAGAR, L SAMUEL WANN \\ From the Cardiology Division, Medical College of Wisconsin, Milwaukee County Medical Complex; and \\ Zablocki Veterans Administration Medical Center, Milwaukee, Wisconsin, USA
}

SUMMARY Doppler echocardiography was used to measure stroke volume, peak flow velocity, and acceleration of flow in the ascending aorta in 10 healthy young volunteers during unlimited supine bicycle exercise and upright treadmill exercise. High quality studies were obtained in all subjects through the suprasternal notch acoustic window; there was no appreciable degradation in Doppler signal caused by interference by increased respiration or chest wall motion. Stroke volume index increased from $54 \mathrm{ml} / \mathrm{m}^{2}$ at rest to $63.5 \mathrm{ml} / \mathrm{m}^{2}$ at peak supine exercise and from 38 $\mathrm{ml} / \mathrm{m}^{2}$ standing at rest to $63.3 \mathrm{ml} / \mathrm{m}^{2}$ during peak upright exercise. Mean peak flow velocity rose from $0.91 \mathrm{~m} / \mathrm{s}$ at supine rest to $1.36 \mathrm{~m} / \mathrm{s}$ during maximum supine exercise. In the upright position mean peak flow velocity increased from $0.75 \mathrm{~m} / \mathrm{s}$ at rest to $1.39 \mathrm{~m} / \mathrm{s}$ during maximum exercise. Mean peak velocities were lower in the upright position at rest but were not significantly different at peak exercise. Mean acceleration of flow in the ascending aorta increased from $12.02 \mathrm{~m} / \mathrm{s}^{2}$ during supine rest to $21.6 \mathrm{~m} / \mathrm{s}^{2}$ during supine exercise and from $10.8 \mathrm{~m} / \mathrm{s}^{2}$ at rest on the treadmill to $21.9 \mathrm{~m} / \mathrm{s}^{2}$ during peak upright exercise.

This study shows that echocardiographic measurement of ascending aortic blood flow by the Doppler technique is feasible even during vigorous exercise; that stroke volume and peak flow velocity at rest are lower in the upright position than in the supine position but equalise at peak exercise; and that acceleration of flow in the ascending aorta is the same in both the supine and upright positions and increases equally at peak exercise in both positions.

The relative contributions of increments in stroke volume and heart rate to the increase in cardiac output which accompanies exercise have been extensively studied with variable and sometimes contradictory results. ${ }^{1-3}$ No change in stroke volume with exercise was found in early studies which used sonocardiometry to monitor left ventricular dimensions during exercise. ${ }^{1}$ Subsequently, several studies used dye dilution ${ }^{4-6}$ or Fick methods ${ }^{7-9}$ to determine cardiac output and they showed an increase in stroke volume with exercise. Whereas invasive and non-invasive studies of the haemodynamic response to exercise have been performed, measurements made during maximal supine

Requests for reprints to Dr L Samuel Wann, Cardiology Division, Medical College of Wisconsin, 8700 West Wisconsin Avenue, Milwaukee, Wisconsin 53226 , USA.

Accepted for publication 22 July 1985 bicycle exercise and maximal upright treadmill exercise in the same subjects have not been compared because of the technical limitations of available methods. Doppler echocardiography is suitable for such measurements and can be used to measure the velocity of blood flow in the ascending aorta during left ventricular ejection. Peak ascending aortic blood flow and acceleration of flow have been correlated with the maximum rate of rise of left ventricular pressure $(\mathrm{dP} / \mathrm{dt})$ and hence left ventricular function. ${ }^{10-13}$ Thus, changes in these variables with exercise may be useful for the non-invasive detection of exercise induced left ventricular dysfunction. Normal values of peak velocity and acceleration of blood flow in the ascending aorta during exercise are not known.

We have investigated the feasibility of performing Doppler echocardiography during exercise to measure the effects of unlimited exercise on stroke vol- 


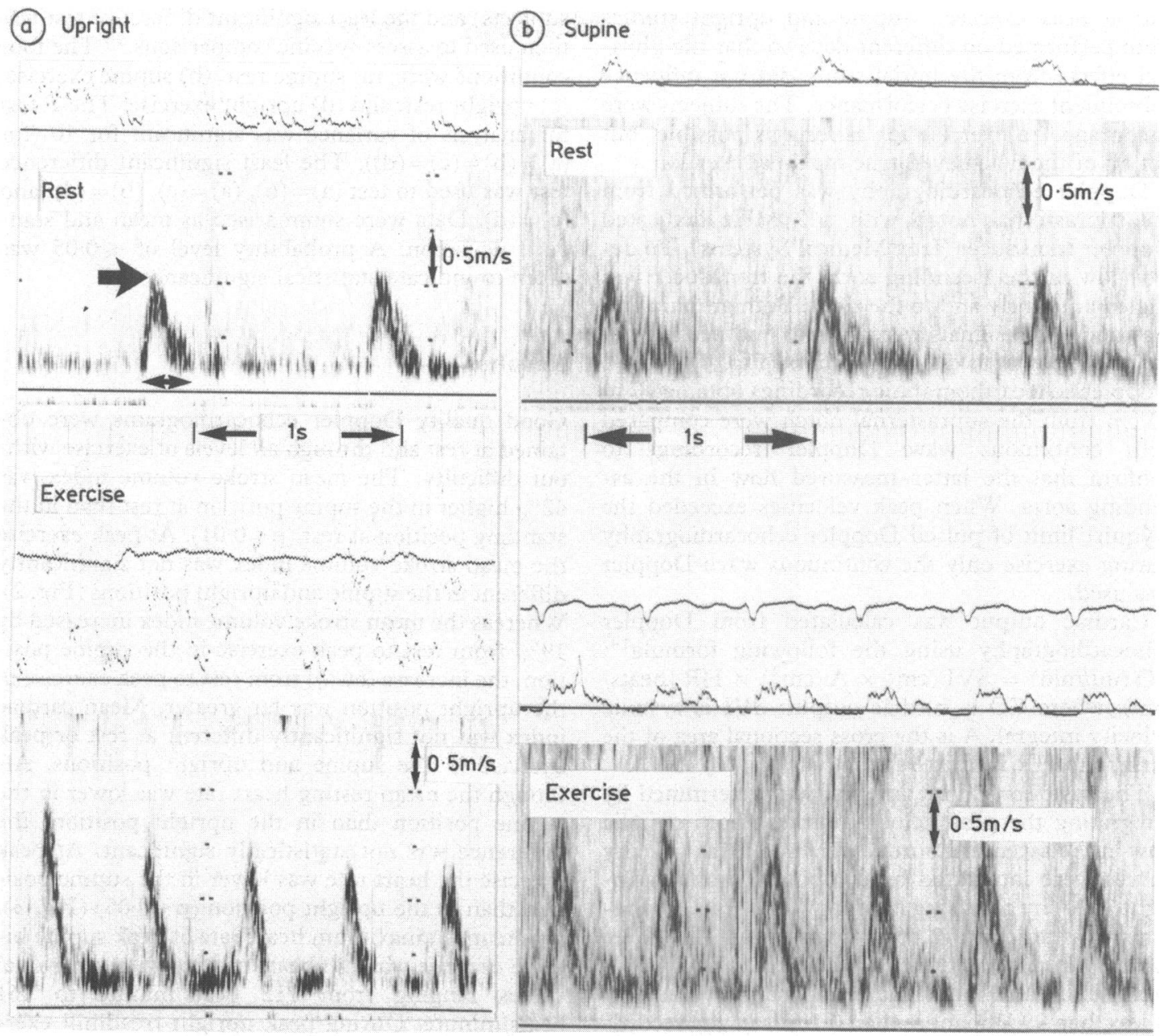

Fig. 1 Continuous wave Doppler echocardiographic recordings from the suprasternal notch at rest and during exercise in the upright (a) and supine (b) positions. Near the first beat during upright rest in (a) peak flow velocity is indicted by a large arrow and ejection time by a smaller double arrow.

ume during supine bicycle exercise and upright treadmill exercise and to obtain normal values for rest and exercise aortic blood flow peak velocities and acceleration.

\section{Subjects and methods}

We studied 10 healthy adults (six men and four women) mean age 27 years (range 25-31 years). None had important cardiac disease. All gave informed consent to a protocol approved by the human studies committee of the Medical College of Wisconsin.

Supine exercise was performed on a bicycle ergometer (Quinton) and was continued until exhaus- tion. The upper body was kept flat with the legs raised to approxiamately $30^{\circ}$. Haemodynamic data were obtained at rest with the feet raised and strapped in place on the bicycle ergometer. Exercise was initiated at $200 \mathrm{kpm} / \mathrm{min}$ and was increased every 3 minutes by $100 \mathrm{kpm} / \mathrm{min}$ (women) or 200 $\mathrm{kpm} / \mathrm{min}(\mathrm{men})(1 \mathrm{kpm} / \mathrm{min}=0.167 \mathrm{~W})$. Upright exercise was performed on an automated treadmill (Marquette CASE) following the Bruce protocol. Subjects exercised until exhaustion. During both supine and upright exercise, heart rate (electrocardiogram) and blood pressure were measured, and Doppler echocardiography was performed at each 3 minute workload. The rate-pressure product (heart rate $\times$ systolic blood pressure) was calculated at rest 
and at peak exercise. Supine and upright studies were performed on different days so that the physical effects from the initial study did not influence subsequent exercise performance. The subjects were encouraged to exercise for as long as possible, but not all of them achieved true maximal exertion.

Doppler echocardiography was performed from the suprasternal notch with a $2 \mathrm{MHz}$ dedicated Doppler transducer (Irex Medical Systems). To detect flow in the ascending aorta the transducer was angled anteriorly and to the right. Both graphic display and audio signals were used to find peak velocity envelopes with distinct borders (Fig. 1). Pulsed Doppler echocardiographic recordings obtained 7 to $10 \mathrm{~cm}$ from the suprasternal notch were compared with continuous wave Doppler recordings to confirm that the latter measured flow in the ascending aorta. When peak velocities exceeded the Nyquist limit of pulsed Doppler echocardiography during exercise only the continuous wave Doppler was used.

Cardiac output was calculated from Doppler echocardiography using the following formula ${ }^{14}$ : $\mathrm{CO}(\mathrm{ml} / \mathrm{min})=\mathrm{SVI}(\mathrm{cm}) \times \mathrm{A}\left(\mathrm{cm}^{2}\right) \times \mathrm{HR}$ (beats $/$ $\mathrm{min}$ ); where $\mathrm{CO}$ is cardiac output; SVI is systolic velocity integral, $A$ is the cross sectional area of the aorta, and HR is heart rate.

The systolic velocity integral was determined by integrating the peak velocity curves (from systolic flow in the ascending aorta) over time. Peak velocity curves were integrated by computer (Franklin Insight 2000) by digitising hardcopy data (Fig. 1). Preliminary studies of 12 recordings obtained in three subjects at rest and during both supine and upright exercise revealed inter- and intraobserver variability of less than $9 \%$, no more than $0.1 \mathrm{~m} / \mathrm{s}$ in any recording. Data for this study were obtained by one observer who was unaware of the other findings or the state of exercise. The cross sectional area of the aorta was determined by measuring the diameter of the aortic root at the annulus with $M$ mode echocardiography guided by cross sectional echocardiography (Irex Medical Systems). ${ }^{14}$ The largest aortic diameter in systole and the diameter at end diastole were averaged. ${ }^{15}$ The area $(\mathrm{A})$ of the aorta at the annulus was calculated as: $A=\pi(\text { diameter } / 2)^{2}$. Cardiac indices were determined by multiplying stroke volume indices and heart rate.

Acceleration of flow in the ascending aorta was determined from hardcopy data and the formula: acceleration $=\mathrm{V}$ peak/TP. Time to peak velocity (TP) was calculated from the time of onset of flow to the time at which velocity of flow was maximal (V peak) (Fig. 1).

Each of the study variables was analysed with a two way analysis of variance (four conditions by 10 subjects) and the least significant difference test was then used to assess specific comparisons. ${ }^{16}$ The four conditions were: (a) supine rest, (b) supine exercise, (c) upright rest, and (d) upright exercise. The F test for analysis of variance was significant for 10 (for $(a)=(b)=(c)=(d))$. The least significant difference test was used to test $(a)=(b),(a)=(c),(b)=(d)$, and $(c)=(d)$. Data were summarised as mean and standard deviation. A probability level of $\leqslant 0.05$ was taken to indicate statistical significance.

\section{Results}

Good quality Doppler echocardiograms were obtained at rest and through all levels of exercise without difficulty. The mean stroke volume index was $42 \%$ higher in the supine position at rest than in the standing position at rest $(\mathrm{p}<0.01)$. At peak exercise the mean stroke volume index was not significantly different in the supine and upright positions (Fig. 2). Whereas the mean stroke volume index increased by $19 \%$ from rest to peak exercise in the supine position, the increase $(66 \%)$ from rest to peak exercise in the upright position was far greater. Mean cardiac index was not significantly different at rest or peak exercise in the supine and upright positions. Although the mean resting heart rate was lower in the supine position than in the upright position, the difference was not statistically significant. At peak exercise the heart rate was lower in the supine position than in the upright position $(\mathrm{p}<0.05)$ (Fig. 3).

The mean maximum heart rate at peak supine bicycle exercise was 138 beats/minute with individual values ranging from 112 beats/minute to 161 beats/minute. During peak upright treadmill exercise the mean maximum heart rate was 151 beats/minute with values ranging from 127 beats/minute to 191 beats/minute.

The mean double product increased with exercise but was not significantly different in the supine and upright positions (Fig. 3). Mean peak blood flow velocity in the ascending aorta was $0.91 \mathrm{~m} / \mathrm{s}$ at supine rest with the feet elevated and increased to $1.36 \mathrm{~m} / \mathrm{s}$ during peak supine exercise (Fig. 4). At rest in the upright position mean peak velocity was $0.75 \mathrm{~m} / \mathrm{s}$ and increased to $1.39 \mathrm{~m} / \mathrm{s}$ during maximum upright exercise. Mean peak velocity was significantly lower in the upright position at rest $(p<0.05)$. than in the supine position but not at peak exercise (Fig. 4). Mean acceleration of blood flow in the ascending aorta increased from $12.02 \mathrm{~m} / \mathrm{s}^{2}$ during supine rest to $21.16 \mathrm{~m} / \mathrm{s}^{2}$ during supine exercise $(\mathrm{p}<0.01)$. In the standing position mean acceleration increased from $10.8 \mathrm{~m} / \mathrm{s}^{2}$ at rest to $21.9 \mathrm{~m} / \mathrm{s}^{2}$ during peak exercise $(p<0.01)$. Mean acceleration was not 


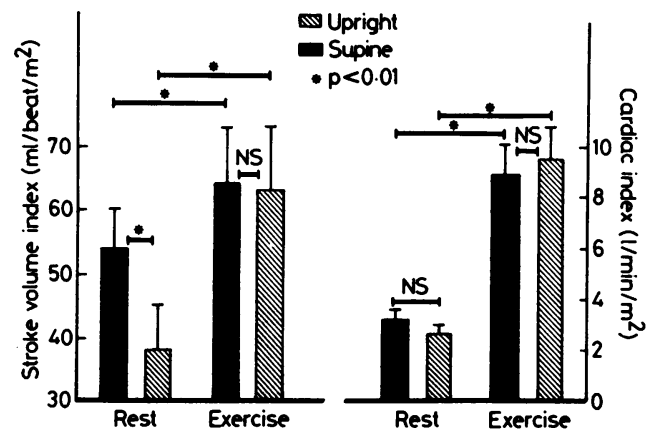

Fig. 2 Changes in mean (SD) stroke volume index and mean (SD) cardiac index during supine and upright exercise. Stroke volume index rose from $53.9(6.3) \mathrm{ml} / \mathrm{beat} / \mathrm{m}^{2}$ in the supine position at rest to $63.5(8.8) \mathrm{ml} / \mathrm{beat} / \mathrm{m}^{2}$ at exercise and from $38(6.7) \mathrm{ml} /$ beat $/ \mathrm{m}^{2}$ upright at rest to 63.3 (9.9) $\mathrm{ml} /$ beat $/ \mathrm{m}^{2}$ at exercise. Cardiac index rose from $3.2(0.4)$ $\mathrm{ml} / \mathrm{min} / \mathrm{m}^{2}$ supine at rest to $8.7(1.5) \mathrm{ml} / \mathrm{min} / \mathrm{m}^{2}$ at exercise and from $2.6(0.3) \mathrm{l} / \mathrm{min} / \mathrm{m}^{2}$ upright at rest to $9.5(1.3)$ $l / \min / \mathrm{m}^{2}$ during upright exercise.

significantly different in the supine and upright positions (Fig. 4).

\section{Discussion}

The effects of exercise on cardiovascular function have intrigued investigators for decades. The response of the heart to increased demand is of fundamental physiological importance and plays a major role in the clinical detection and quantification of
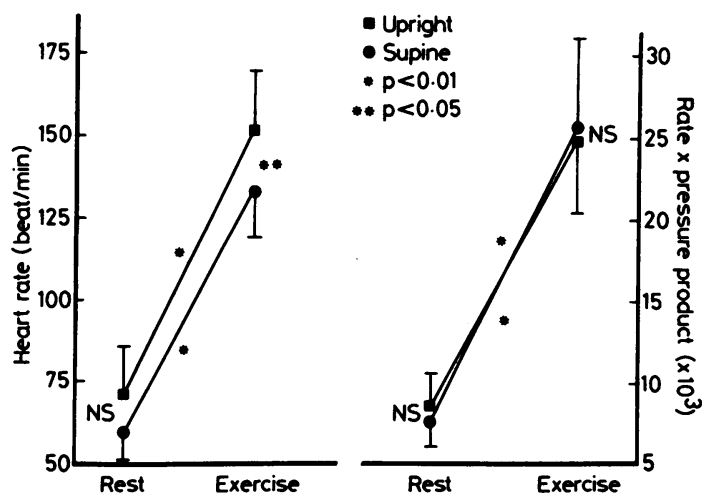

Fig. 3 Changes in mean (SD) heart rate and mean (SD) rate-pressure product during supine and upright exercise. Heart rate rose from 60 (9) beats/min at supine rest to 138 (16) beats/min at exercise and from 71 (15) beats/min at upright rest to 151 (21) beats/min during exercise. Rate pressure product rose from $7.8(1.7)$ at supine rest to 25.5 (5.5) at exercise and from 8.7 (8) at upright rest to 25 (5) at exercise.

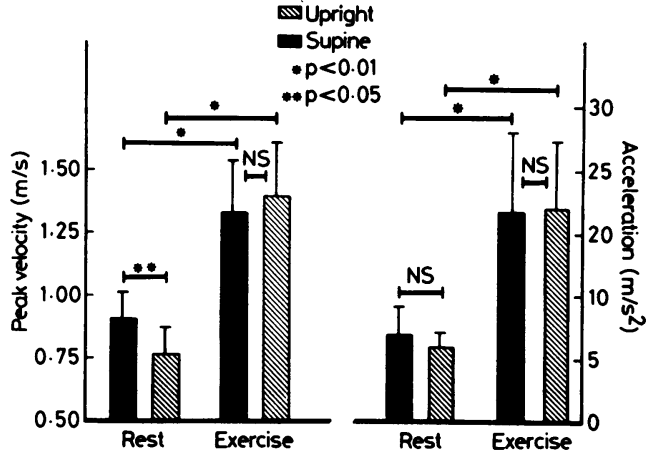

Fig. 4 Changes in mean (SD) peak flow velocity and mean (SD) acceleration of flow in the ascending aorta during exercise. Peak flow velocity during supine rest was 0.9 (0.1) $\mathrm{m} / \mathrm{s}$ rising to $1.4(0.2) \mathrm{m} / \mathrm{s}$ with exercise. Upright resting peak velocity was $0.8(0.1) \mathrm{m} / \mathrm{s}$ rising to $1.4(0.3) \mathrm{m} / \mathrm{s}$ with exercise.

heart disease. While many studies have been performed to evaluate the haemodynamic response to exercise in the supine and upright positions, accurate methods of measuring variables such as stroke volume, peak velocity of ascending aortic blood flow, and acceleration of flow during high levels of exercise in both the supine and upright positions have only recently become available. The accuracy of Doppler echocardiography in measuring stroke volume in subjects at rest has been clearly demonstrated. ${ }^{1417-19}$ The technique has also been used during low-level exercise in patients with mitral stenosis $^{20}$ and in normal subjects. ${ }^{21}$

We have shown that Doppler echocardiography in which the suprasternal notch is used as an acoustic window can be performed in normal subjects during rigorous exercise. Respiratory interference during exercise was not a major problem because the ultrasound beam traversed the mediastinum to reach the ascending aorta and did not come into contact with the lung. In addition, lower frequency ultrasound has a better penetrating capacity and can be successfully used in Doppler echocardiography. The high signal to noise ratio of the dedicated continuous wave Doppler system we used was particularly useful in obtaining diagnostic quality data at peak exercise. While the success rate will probably be less when large numbers of patients rather than healthy subjects are studied with this technique, the ease with which we were able to record Doppler signals during exercise is encouraging.

We found an increase in stroke volume and peak velocity of flow in the ascending aorta with exercise. 
Table Stroke volume index measured by Doppler echocardiography during supine and upright rest and exercise

\begin{tabular}{|c|c|c|c|c|c|c|}
\hline & \multicolumn{4}{|c|}{ Stroke volume index $\left(\mathrm{ml} / \mathrm{m}^{2}\right)$} & \multicolumn{2}{|l|}{ Method } \\
\hline & \multicolumn{2}{|c|}{ Supine } & \multicolumn{2}{|c|}{ Upright } & \multirow[t]{2}{*}{ Cardiac output } & \multirow{2}{*}{$\begin{array}{l}\text { Upright } \\
\text { exercise }\end{array}$} \\
\hline & $\overline{\text { Rest }}$ & Exercise & $\overline{\text { Rest }}$ & Exercise & & \\
\hline $\begin{array}{l}\text { Wang et al }(1960)^{6} \\
\text { Frick and Somer }(1964)^{8} \\
\text { Bevegåd et al }(1966)^{7} \\
\text { Poliner et al }(1980)^{24}\end{array}$ & $\begin{array}{l}53 \\
51 \\
56 \\
42\end{array}$ & $\begin{array}{l}60 \\
68 \\
68 \\
58\end{array}$ & $\frac{32}{38}$ & $\begin{array}{l}59 \\
63 \\
54\end{array}$ & \multirow[t]{2}{*}{$\begin{array}{l}\text { Dye } \\
\text { Fick } \\
\text { Fick } \\
\text { Radionuclide } \\
\text { angiography } \\
\text { Doppler }\end{array}$} & $\begin{array}{l}\text { Treadmill } \\
\overline{\text { Bicycle }} \\
\text { Bicycle }\end{array}$ \\
\hline Medical College of Wisconsin & 54 & 64 & 38 & 63 & & Treadmill \\
\hline
\end{tabular}

^All supine exercise performed on bicycle.

At rest, stroke volume and peak velocity are greater in the supine than the upright position. Heart rate is slightly higher in the upright position to maintain cardiac output. During exercise in the supine position, stroke volume and peak velocity increase but not nearly to the degree that they increase in the upright position. During peak exercise, stroke volume and peak velocity are not significantly different in the supine and upright positions. Acceleration of flow in the ascending aorta increased with exercise but was not significantly different in the supine and upright positions, suggesting that this variable is independent of preload (Frank-Starling phenomenon).

The mechanism responsible for postural differences in the haemodynamic response to exercise is uncertain. ${ }^{127}$ Changes in stroke volume during exercise were not found in early studies, ${ }^{1}$ but most subsequent data, like ours, showed an increase in stroke volume during exercise. ${ }^{71522}$ Increased myocardial contractility contributes to the increase in stroke volume with exercise. ${ }^{23}$ The role of the Frank-Starling mechanism is controversial; however, recent data suggest that stroke volume during exercise is increased by a combination of the FrankStarling mechanism and an enhanced contractile state. ${ }^{24-26}$ Changes in the preload of the left ventricle also contribute to changes in stroke volume. Venous return is augmented in the supine position and this contributes to the greater stroke volume achieved. Raising the legs and strapping feet into place on the bicycle ergometer increased stroke volume by $19 \%$ compared with stroke volume in the supine, legs flat position. ${ }^{8}$ The muscle pump action of the legs is important in augmenting venous return in the upright position. During upright exercise when only the arms are used stroke volume is lower throughout exercise and never rises as high as stroke volume during upright exercise with the legs. ${ }^{37} \mathrm{Fi}$ nally, changes in systemic impedance are also of importance in causing changes in stroke volume. ${ }^{27}$
Thus increases in stroke volume with exercise are brought about by various interacting mechanisms. Our data show that these mechanisms result in similar stroke volumes at peak exercise in the supine and upright positions whereas at rest stroke volume is lower in the upright position.

In the Table we compare our results with those obtained in other studies of normal volunteers of similar age that used invasive techniques and radionuclide ventriculography. Using the cardiogreen dye indicator dilution method during supine and upright exercise, Wang $e a^{6}{ }^{6}$ showed changes in cardiac output nearly identical to ours. Bevegård et al ${ }^{7}$ and Frick and Somer ${ }^{8}$ used the Fick principle to show changes in cardiac output with supine and upright exercise similar to those we demonstrated with Doppler echocardiography. Using radionuclide ventriculography, Poliner et al reported lower resting stroke volume indices than those found by others and they did not detect an increase in stroke volume with elevation of the legs in the supine position. ${ }^{24}$ The fact that our measurements of stroke volume by Doppler echocardiography correlated closely with stroke volume determined invasively confirms the accuracy of the Doppler technique.

We also measured peak velocity and acceleration of flow in the ascending aorta at rest and during exercise. In previous invasive studies a correlation between ascending aortic blood flow velocity and left ventricular function was noted. ${ }^{10-12}$ Acceleration of flow has been related to $\mathrm{dP} / \mathrm{dt}$ and thus is regarded as an index of left ventricular function ${ }^{10-13}$ Similarly, changes in peak flow velocity have been shown to reflect changes in left ventricular contraction induced by positive inotropic stimulation. ${ }^{10}$ After intravenous propranolol, depression in myocardial function can be detected by decreases in maximal blood flow velocity, acceleration, and $\mathrm{dP} / \mathrm{dt} .{ }^{12}$ Our data for peak flow velocity and acceleration are similar to those obtained by electromagnetic velocity sensors. ${ }^{12}$ Measurement of ascending aortic blood flow 
velocity and acceleration by Doppler echocardiography provides a non-invasive means of assessing left ventricular function. Monitoring of these variables during exercise may allow detection of exercise induced left ventricular dysfunction.

Exercise Doppler echocardiography may have several limitations. We used an average of systolic and diastolic potential diameters to calculate cardiac output. ${ }^{1428}$ Since we were unable to measure the aortic annulus diameter during exercise, we used the resting value to calculate stroke volume during exercise. This seems reasonable since aortic dimensions at the annulus do not change significantly when cardiac outputs are increased fourfold with dobutamine infusion. ${ }^{14}$ In an animal model too, it has been shown that aortic dimensions do not change significantly over a wide range of cardiac outputs. ${ }^{29}$ Nevertheless, determination of aortic diameter is a well known source of error when Doppler echocardiography is used to measure stroke volume.

Limitations in Doppler instrumentation and technique may prevent accurate recording of peak velocity profiles, especially if only pulsed wave Doppler echocardiography is used. Care must be taken to locate the peak velocity profile when the interrogating beam is parallel to flow in the ascending aorta. There may be difficulties when this method is used in older patients with cardiac disease who may not have laminar flow in the ascending aorta.

We have demonstrated that stroke volume, peak velocity, and acceleration of ascending aortic blood flow can be measured by Doppler echocardiography during vigorous supine bicycle exercise and upright treadmill exercise. Different responses to supine and upright exercise were shown by the technique, which appears to have considerable potential for evaluation of patients with known or suspected heart disease.

We thank Dr John H Kalbfleisch for the statistical analysis.

This study was supported in part by the NIH/NHLBI, Bethesda, Maryland, the Veterans Administration, Washington, DC, and the American Heart Association, Milwaukee, Wisconsin, USA.

\section{References}

1 Rushmer RF. Constancy of stroke volume in ventricular responses to exertion. Am F Physiol 1959; 196: 745-50.

2 Gorlin R, Cohen LS, Elliott WC, Klein MD, Lane FJ. Effect of supine exercise on left ventricular volume and oxygen consumption in man. Circulation 1965; 32: 361-71.

3 Stenberg J, Asstrand P-O, Ekblom B, Royce J, Saltin B. Hemodynamic response to work with different muscle groups, sitting and supine. 3 Appl Physiol 1967; 22: 61-70.

4 Grimby G, Nilsson NJ, Saltin B. Cardiac output during submaximal and maximal exercise in active middle-aged athletes. $\mathcal{f}$
Appl Physiol 1966; 21: 1150-6.

5 Theilen EO, Gregg DE, Rotta A. Exercise and cardiac work response at high altitude. Circulation 1955; 12: 383-90.

6 Wang Y, Marshall RJ, Shepherd JT. The effect of changes in posture and of graded exercise on stroke volume in man. $\mathcal{f}$ Clin Invest 1960; 39: 1051-61.

7 Bevegard S, Freyschuss U, Strandell T. Circulatory adaptation to arm and leg exercise in supine and sitting position. I Appl Physiol 1966; 21: 37-46.

8 Frick $M H$, Somer T. Base-line effects on response of stroke volume to leg exercise in the supine position. $\mathcal{f}$ Appl Physiol 1964; 19: 639-46.

9 Reeves JT, Grover RF, Blount SG Jr, Filley GF. Cardiac output response to standing and treadmill walking. 9 Appl Physiol 1961; 16: 283-8.

10 Noble MIM, Trenchard D, Guz A. Left ventricular ejection in conscious dogs: I. Measurement and significance of the maximum acceleration of blood from the left ventricle. Circ Res 1966; 19: 139-47.

11 Kolettis M, Jenkins BS, Webb-Peploe MM. Assessment of left ventricular function by indices derived from aortic flow velocity. Br Heart \& 1976; 38: 18-31.

12 Klinke WP, Christie LG, Nichols WW, et al. Use of cathetertip velocity-pressure transducer to evaluate left ventricular function in man: effects of intravenous propranolol. Circulation 1980; 61: 946-54.

13 Rushmer RF. Initial ventricular impulse. A potential key to cardiac evaluation. Circulation 1964; 29: 268-83.

14 Ihlen H, Amlie JP, Dale J, et al. Determination of cardiac output by Doppler echocardiography. Br Heart $\mathcal{F} 1984$; 51: 54-60.

15 Crawford MH, White DH, Amon KW. Echocardiographic evaluation of left ventricular size and performance during handgrip and supine and upright bicycle exercise. Circulation 1979; 59: 1188-96.

16 Snedecor GW, Cochran WG. Statistical methods. 6th ed. Ames, Iowa: Iowa State University Press, 1969.

17 Huntsman LL, Stewart DK, Barnes SR, Franklin SB, Colocousis JS, Hessel EA. Noninvasive Doppler determination of cardiac output in man: clinical validation. Circulation 1983; 67: 593-602.

18 Magnin PA, Stewart JA, Myers S, Von Ramm O, Kisslo JA. Combined Doppler and phased-array echocardiographic estimation of cardiac output. Circulation 1981; 63: 388-92.

19 Nishimura RA, Callahan MJ, Schaff HV, Ilstrup DM, Miller FA, Tajik AJ. Noninvasive measurement of cardiac output by continuous wave Doppler echocardiography: initial experience and review of the literature. Mayo Clin Proc 1984; 59: 484-9.

20 Hatle L, Angelsen B. Doppler ultrasound in cardiology. Philadelphia: Lea and Feibiger, 1985: 110.

21 Loeppky JA, Greene ER, Hoekenga DE, Caprihan A, Luft UC. Beat-by-beat stroke volume assessment by pulsed Doppler in upright and supine exercise. I Appl Physiol 1981; 50: 1173-82.

22 Wilson MF. Left ventricular diameter, posture, and exercise. Circ Res 1962; 11: 90-5.

23 Parker JO, Case RB. Normal left ventricular function. Circulation 1979; 60: 4-12.

24 Poliner LR, Dehmer GJ, Lewis SE, Parkey RW, Blomqvist CG, Willerson JT. Left ventricular performance in normal subjects: a comparison of the response to exercise in the upright and supine positions. Circulation 1980; 62: 528-34.

25 Horwitz LD, Atkins JM, Leshin SJ. Role of the Frank-Starling mechanism in exercise. Circ Res 1972; 31: 868-75.

26 Vatner SF, Franklin D, Higgins CB, Patrick T, Braunwald E. Left ventricular response to severe exertion in untethered dogs. f Clin Invest 1972; 51: 3052-60.

27 Noble MIM, Trenchard D, Guz A. Left ventricular ejection in conscious dogs: II. Determinants of stroke volume. Circ Res 1966; 19: 148-52.

28 Greenfield JC Jr, Patel DJ. Relation between pressure and diameter in the ascending aorta of man. Circ Res 1962; 10: 778-81.

29 Colocousis JS, Huntsman LL, Curreri PW. Estimation of stroke volume changes by ultrasound Doppler. Circulation 1977; 56: 914-7. 